\title{
Effects of androgens on sexual behaviour and somatic variables in the male golden hamster
}

\author{
A. P. Payne and N. K. Bennett \\ Department of Anatomy, The University, Glasgow G12 8QQ, U.K.
}

\begin{abstract}
Summary. Comparisons were made of the sexual behaviour of sham-operated male hamsters and castrated males receiving testosterone, dihydrotestosterone or androstenedione $(1.5 \mathrm{mg} /$ week $)$, or oil alone. Tests of short duration $(10 \mathrm{~min})$ were conducted at Week 3 (when the animals were sexually naive), Week 6 and Week 9 . Sham-operated males showed marked increases in many elements of behaviour between Weeks 3 and 9 , while castrated males receiving no androgen replacement showed marked decreases. Males receiving each of the three androgens showed marked increases in behaviour, but androstenedione-treated males showed less facilitation of sexual behaviour than controls. Dihydrotestosterone was as effective as testosterone. The three androgens were comparable in maintaining seminal vesicle weight after castration and in preventing the customary rise in pituitary and body weights. These data suggest that, unlike the situation in the rat, aromatization of androgens is unnecessary for the display of sexual behaviour in the hamster.
\end{abstract}

\section{Introduction}

Since the demonstration that testosterone can be reduced to its metabolite $5 \alpha$-dihydrotestosterone or aromatized to oestrogens at target tissues within the central nervous system (Kniewald, Massa \& Martini, 1970; Weisz \& Gibbs, 1974; Minguell \& Sierralta, 1975), there has been much interest in the possible roles of androgens and their naturally occurring metabolites in mediating 'androgendependent' behaviour. It has been shown that, while $5 \alpha$-dihydrotestosterone will maintain the integrity of the reproductive tract in castrated rats, it cannot maintain sexual behaviour (McDonald et al., 1970; Feder, 1971; Whalen \& Luttge, 1971); normal mounting and ejaculatory responses are, however, achieved after the simultaneous administration of small amounts of oestradiol (Baum \& Vreeburg, 1973; Larsson, Södersten \& Beyer, 1973; Feder, Naftolin \& Ryan, 1974). Because $5 \alpha$-dihydrotestosterone cannot be aromatized, it has been suggested that testosterone may maintain (i) the reproductive tract via its reduced $5 \alpha$-dihydrotestosterone metabolite and (ii) reproductive behaviour via aromatization within the central nervous system to oestradiol.

In contrast, dihydrotestosterone has been shown to maintain sexual behaviour in the male rhesus monkey (Phoenix, 1974) and the guinea-pig (Alsum \& Goy, 1974), and in some strains of mice it appears capable of maintaining sexual (Luttge \& Hall, 1973a) and aggressive (Luttge \& Hall, 1973b) behaviour. In the golden hamster dihydrotestosterone can maintain aggressive behaviour (Payne, 1974), but its effect on sexual behaviour is equivocal; Christensen, Coniglio, Paup \& Clemens (1973) found it ineffective, while Whalen \& DeBold (1974) reported that it maintained intromission and ejaculatory responses, although not at as low a dosage as testosterone.

In the present experiment, therefore, the effects of relatively small doses of testosterone, $5 \alpha$ dihydrotestosterone and $\Delta^{4}$-androstenedione on the sexual behaviour of castrated male golden hamsters were re-examined.

\section{Materials and Methods}

\section{Animals}

Seventy cream male golden hamsters of closed colony stock (established 1968) were separated into single-sex groups at weaning (21-24 days after birth), before the development of sexual behaviour 
(about 3540 days: Whitsett \& Vandenbergh, 1975). As adults (i.e.>4-5 months), 57 males were bilaterally castrated and allocated to one of the following treatment groups: Group 1, 1.5 mg testosterone in $0.3 \mathrm{ml}$ arachis oil/week $(\mathrm{N}=14)$; Group $2,1.5 \mathrm{mg} 5 \alpha$-dihydrotestosterone in $0.3 \mathrm{ml}$ arachis oil/week $(\mathrm{N}=16)$; Group $3,1.5 \mathrm{mg} \Delta^{4}$-androstenedione in $0.3 \mathrm{ml}$ arachis oil/week $(\mathrm{N}=13)$; and Group 4, $0.3 \mathrm{ml}$ arachis oil. All treatments were given in equal, thrice-weekly s.c. injections (for steroid treatments $500 \mu \mathrm{g}$ per injection) for a period of 9 weeks. The remaining 13 males were subjected to sham-operation.

\section{Observations}

At 3, 6 and 9 weeks after operation all males were observed with a receptive female for a single, 10-min period during which the frequencies of the following components of behaviour were recorded. (i) Mounting. This included all attempts at mounting the receptive female, whether correctly orientated or not. (Naive males often mount any part of the female, especially the head and flanks.) (ii) Intromission. A pronounced pelvic thrust by a mounting animal which signified penile insertion. (iii) Genital grooming. This frequently occurred between mounts, particularly if intromission was successful. (iv) Licking of the vulval region. (v) Tugging. The male gripped the lordotic female in his teeth and moved her bodily. This infrequent behaviour occurred particularly in interactions during which the female assumed lordosis in an inaccessible position, e.g. with her rear against the cage side. (vi) The latency to the first mount was also recorded.

All animals were weighed immediately after operation and at 3,6 and 9 weeks at the time of testing. After 9 weeks all the animals were killed and the wet weight of pituitary and seminal vesicles (after extrusion of the contents) was recorded.

\section{Statistical analyses}

For each group of males, the frequencies of behavioural components were compared between the first (Week 3) and the third (Week 9) observation periods by means of the Wilcoxon matchedpairs test. In addition the behaviour during Weeks 3 and 9 was compared for all the groups by means of the Kruskal-Wallis one-way analysis of variance $(\mathrm{H})$; when such an analysis proved significant, individual paired comparisons were made using the Mann-Whitney $U$ test. Somatic variables were compared between the five groups by analyses of variance $(F)$. When an analysis proved significant, Tukey's HSD multiple-comparison test was performed to determine the direction of significant differences.

\section{Results}

\section{Mounting, intromission, and genital grooming (see Table I)}

At 3 weeks after operation there were no significant variances between the 5 groups for these components of sexual behaviour. Sham-operated males exhibited very significant increases in all these behavioural variables and a significant decrease in the latency to mounting between Week 3 and Week 9, amounting to a doubling in the frequency of sexual activity. These changes were paralleled by the castrated males receiving testosterone, dihydrotestosterone or androstenedione, except for the intromission scores of the androstenedione-treated animals. By contrast, the castrated males receiving oil alone showed a significant decrease in mounting and intromission (and an increase in the latency to mounting) between Weeks 3 and 9. At Week 9 there were significant variances between the 5 groups for all these measures of sexual behaviour (in all cases, $P<0.001$ ).

Individual comparisons between the groups at Week 9 demonstrate that oil-treated castrates differed from sham-operated controls in all these aspects of behaviour (for all, $P<0.01$ ). Moreover, although the androstenedione-treated males showed the predicted significant increases in behaviour between Tests 1 and 3, at Test 3 they showed significantly less mounting and intromission (for both, $P<0.01)$ and less genital grooming $(P<0.05)$ than the controls, although mount latencies did not 


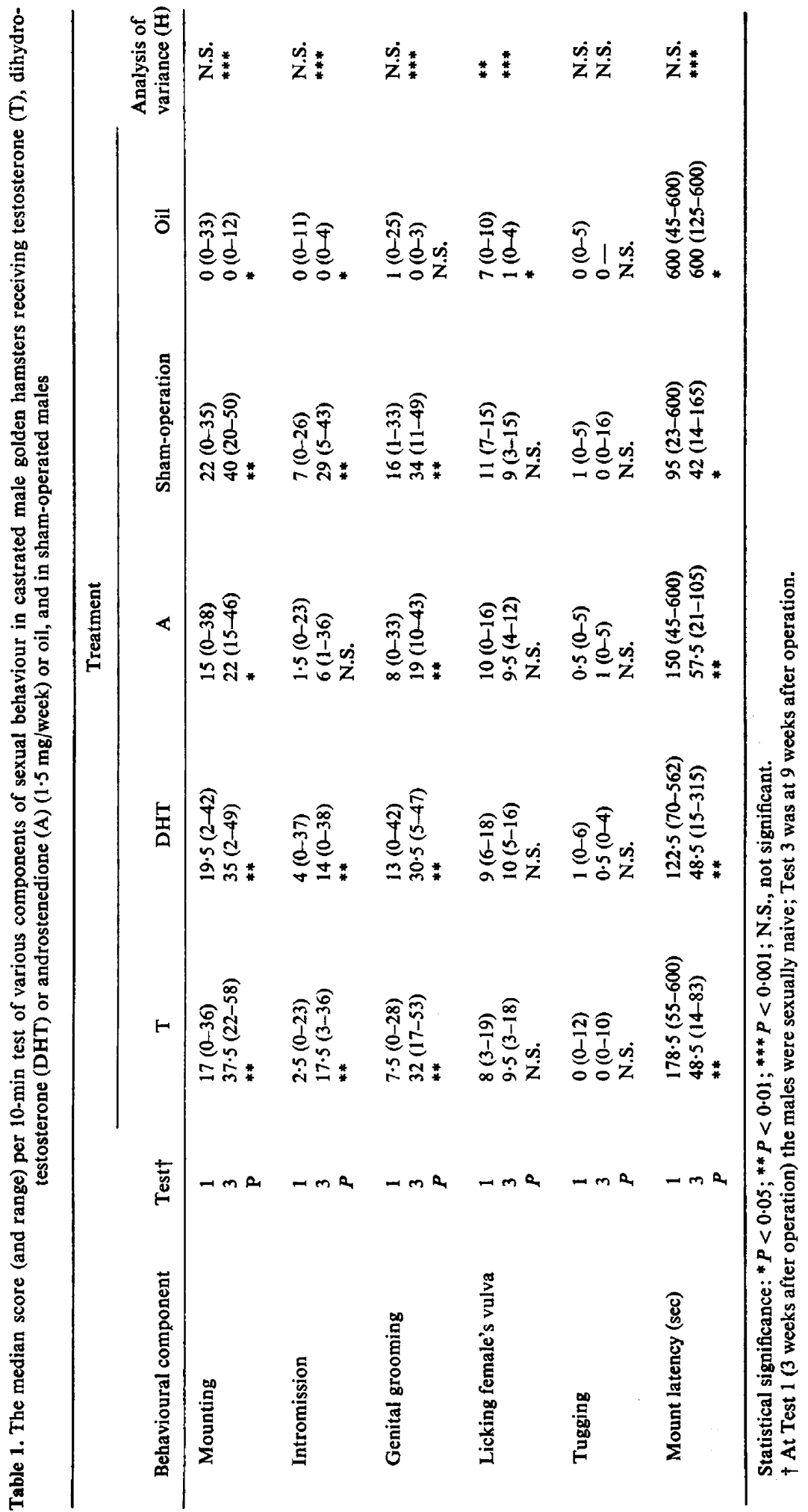


differ. Testosterone-treated males did not differ from controls with regard to any of these measures, while dihydrotestosterone-treated males showed comparable mount latencies and levels of mounting and genital grooming to sham-operated males, but significantly less intromission $(P<0 \cdot 05)$. However, the dihydrotestosterone-treated males did not differ from the testosterone-treated ones on any behavioural measure.

\section{Vulval licking and tugging (see Table I)}

These behavioural components differed from the above in two respects; they occurred less frequently and did not show an increase over the three tests. Significant differences between the 5 groups were found at Week 3 in that castrated males receiving no androgen replacement licked the female's vulva significantly less than did sham-operated controls $(P<0.01)$; moreover, this behaviour declined significantly between Weeks 3 and 9 in the castrates, but remained constant in the controls and the androgen-treated groups. Tugging occurred so infrequently that no statistical differences could be found between the groups, although castrated controls tugged less than the males in the other groups.

\section{Somatic variables (see Table 2)}

Pituitary weight, seminal vesicle weight and the percentage increase in body weight showed highly significant variances between the 5 groups. Castrated males receiving oil alone had smaller seminal vesicles $(P<0.01)$, larger pituitaries $(P<0.01)$ and showed a far greater weight increase during the experiment $(P<0 \cdot 01)$ than the sham-operated controls. The three androgen treatments did not differ from one another in ability to maintain seminal vesicle weight; pituitary weights were also similar. Dihydrotestosterone was less effective than testosterone in maintaining body weight after castration $(P<0.05)$. No androgen-treated animals had seminal vesicle weights as high, or pituitary weights as low, as those of the sham-operated males, suggesting that the dose of androgen was not a complete replacement.

Table 2. The mean ( \pm S.E.M.) seminal vesicle weights, pituitary weights and $\%$ changes in body weight at 9 weeks after operation of sham-operated male hamsters and castrated males receiving dihydrotestosterone (DHT), testosterone (T), or androstenedione (A) $(1.5 \mathrm{mg} /$ week $)$ or oil

\begin{tabular}{|c|c|c|c|c|c|c|}
\hline & \multicolumn{5}{|c|}{ Treatment } & \multirow[b]{2}{*}{$\begin{array}{l}\text { Analysis of } \\
\text { variance (F) }\end{array}$} \\
\hline & $\begin{array}{l}\text { Sham- } \\
\text { operation }\end{array}$ & DHT & $\mathrm{T}$ & A & Oil & \\
\hline $\begin{array}{l}\text { Weight of seminal vesicles } \\
(\mathrm{mg} / 100 \mathrm{~g} \text { body } \mathrm{wt})\end{array}$ & $470 \pm 44$ & $353 \pm 16$ & $316 \pm 25$ & $316 \pm 17$ & $45 \pm 6$ & $39 \cdot 1^{*}$ \\
\hline Pituitary wt (mg) & $2 \cdot 6 \pm 0 \cdot 1$ & $3.7 \pm 0.2$ & $4 \cdot 0 \pm 0 \cdot 3$ & $4 \cdot 8 \pm 0 \cdot 3$ & $5 \cdot 2 \pm 0.6$ & $12 \cdot 1^{*}$ \\
\hline$\%$ Change in body wt & $6 \cdot 1 \pm 2 \cdot 3$ & $18 \cdot 9 \pm 1.9$ & $3.9 \pm 1.6$ & $10 \cdot 7 \pm 2 \cdot 3$ & $36 \cdot 2 \pm 6 \cdot 5$ & $17 \cdot 7^{*}$ \\
\hline
\end{tabular}

Statistical significance: $* P<0.001$.

\section{Discussion}

From the present results, testosterone, $5 \alpha$-dihydrotestosterone and androstenedione may all be judged effective at promoting sexual behaviour in the male hamster, in that males which received them showed significantly more sexual behaviour during Test 3 (at Week 9 after operation) than during Test 1 (at Week 3 after operation). However, androstenedione could not maintain behaviour at the levels shown by the sham-operated control males, whereas testosterone was completely effective. Dihydrotestosterone maintained all elements of behaviour except the frequency of intromission, although intromission scores for the testosterone-treated males differed from those of the 
controls only at the $P<0.10$ level. There were no differences between the testosterone and dihydrotestosterone-treated males as regards any element of behaviour.

These observations confirm those of Whalen \& DeBold (1974) that dihydrotestosterone can maintain sexual behaviour in the male hamster. In the present experiment this conclusion is based on (i) data from sexually naive males whereas Whalen \& DeBold used experienced ones (a condition which may ameliorate post-castration changes in sexual behaviour), and (ii) data obtained using a replacement dose of hormone $(1.5 \mathrm{mg} /$ week $)$ substantially lower than that which Whalen \& DeBold found necessary (1 mg/day). Both Whalen \& DeBold (1974) and Christensen et al. (1973) found androstenedione to be very effective at maintaining sexual behaviour, whereas here it was the least effective androgen. This is surprising because of its potency in facilitating aggression in the male hamster (Payne, 1974), but it does demonstrate that in this present experiment an aromatizable androgen was not as behaviourally potent as a non-aromatizable one. Nor can the ineffectiveness of androstenedione be attributed to a failure to maintain somatic variables. Christensen et al. (1973) reported that androstenedione (as well as testosterone and dihydrotestosterone) could maintain penile papillae and in the present study it maintained seminal vesicle, body and pituitary weights as effectively as the other androgens.

It may be that androgens control sexual behaviour in the golden hamster simply by maintaining the integrity of the reproductive tract and that dihydrotestosterone is therefore effective because of its peripheral potency. This seems unlikely since the prenatal administration of anti-androgens which inhibit development of the genitalia in male hamsters does not appear to affect adult mounting rates (Swanson, 1971). Alternatively, in view of the findings of Baum \& Vreeburg (1973) and Larsson, Södersten \& Beyer (1973), it could be argued that dihydrotestosterone is only effective peripherally in the hamster but is complemented by oestrogens of (say) adrenal origin which act centrally. While these possibilities cannot be ruled out, neither explain the relative ineffectiveness of androstenedione which seems equally capable of maintaining the reproductive tract. Nor do they explain how dihydrotestosterone can facilitate aggression in a test situation where peripheral effects seem unlikely (Payne, 1974). Furthermore, dihydrotestosterone has been shown to decrease female sexual behaviour when administered neonatally to female hamsters (Gerall, McMurray \& Farrell, 1975; Payne, 1976). However, the critical question of whether intracranial implants of dihydrotestosterone can maintain sexual behaviour in the castrated male hamster remains untested.

\section{References}

Alsum, P. \& GoY, R.W. (1974) Actions of esters of testosterone, dihydrotestosterone or oestradiol on sexual behaviour in castrated male guinea-pigs. Horm. \& Behav. 5, 207-217.

Baum, M.J. \& VReeburG, J.T.M. (1973) Copulation in castrated male rats following combined treatment with estradiol and dihydrotestosterone. Science, N.Y. 182, 283-285.

Christensen, L.W., Coniglio, L.P., Paup, D.C. \& Clemens, L.G. (1973) Sexual behaviour of male golden hamster receiving diverse androgen treatments. Horm. \& Behav. 4, 223-229.

FEDER, H.H. (1971) The comparative actions of testosterone propionate and $5 \alpha$-androstan-17 $\beta$-ol-3-one propionate on the reproductive behaviour, physiology and morphology of male rats. J. Endocr. 51, 241-252.

Feder, H.H., Naftolin, F. \& Ryan, K.J. (1974) Male and female sexual responses in male rats given estradiol benzoate and $5 \alpha$-androstan-17 $\beta$-ol-3-one propionate. Endocrinology 94, 136-141.

Gerall, A.A., McMurray, M.M. \& Farrell, A.
(1975) Suppression of the development of female hamster behaviour by implants of testosterone and non-aromatizable androgens administered neonatally. $J$. Endocr. 67, 439-445.

Kniewald, Z., Massa, R. \& Martini, L. (1970) Conversion of testosterone into $5 \alpha$-androstan-17 $\beta$-ol-3one at the anterior pituitary and hypothalamic level. Proc. 3rd Int. Congr. Hormonal Steroids, Hamburg, pp. 784-791. Eds V. H. J. James \& L. Martini. Excerpta Medica Foundation, Amsterdam.

Larsson, K., Södersten, P. \& Beyer, C. (1973) Induction of sexual behaviour by oestradiol benzoate in combination with dihydrotestosterone. J. Endocr. 57, 563-564.

Luttge, W.G. \& Hall, N.R. (1973a) Differential effectiveness of testosterone and its metabolites in the induction of male sexual behavior in two strains of albino mice. Horm. \& Behav. 4, 31-43.

LuTtGe, W.G. \& HaLl, N.R. (1973b) Androgeninduced agonistic behavior in castrated male Swiss-Webster mice: comparison of four naturally : occurring androgens. Behav. Biol. 8, 725-732. 
McDonald, P., Beyer, C., Newton, F., Brien, B., Baker, R., Jan, H.S., Simpson, C., Kitching, P., Greenhill, R. \& Pritchard, D. (1970) Failure of $5 \alpha$-dihydrotestosterone to initiate sexual behaviour in the castrated male rat. Nature, Lond. 277, 964-968.

Minguell, J.J. \& Sierralta, W.D. (1975) Molecular mechanism of action of the male sex hormones. J. Endocr. 65, 287-315.

PAyNe, A.P. (1974) A comparison of the effects of androstenedione, dihydrotestosterone and testosterone propionate on aggression in the castrated male golden hamster. Physiol. Behav. 13, 21-36.

PAYNE, A.P. (1976) A comparison of the effects of neonatally administered testosterone, testosterone propionate and dihydrotestosterone on aggressive and sexual behaviour in the female golden hamster. J. Endocr. 69, 23-31.

Phoenix, C.H. (1974) Effects of dihydrotestosterone on sexual behavior of castrated male rhesus monkeys. Physiol. Behav. 12, 1045-1055.
Swanson, H.H. (1971) Determination of the sex role in hamsters by the action of sex hormones in infancy. In The Influence of Hormones on the Nervous System, pp. 424-440. Ed. D. H. Ford. Karger, Basel.

Weisz, J. \& GibBs, C. (1974) Conversion of testosterone and androstenedione to estrogens in vitro by the brain of female rats. Endocrinology 94, 616-620.

Whalen, R.E. \& DeBold, J.F. (1974 Comparative effectiveness of testosterone, androstenedione and dihydrotestosterone in maintaining mating behavior in the castrated male hamster. Endocrinology 95, 1674-1679.

Whalen, R.E. \& Luttge, W.G. (1971) Testosterone, androstenedione and dihydrotestosterone: effects on mating behavior of male rats. Horm. \& Behav. 2, $117-125$.

WhitSETT, J.M. \& VANDENBERGH, J.G. (1975) Influence of testosterone propionate administered neonatally on puberty and bisexual behavior in female hamsters. J. comp. Physiol. Psychol. 88, 248-255.

Received 31 October 1975 